\title{
Prediction of Outcomes in Victims with Severe Trauma by Statistical Models
}

Juraj Šteňo', Valeriy Boyko ${ }^{2,3}$, Petro Zamiatin ${ }^{2,3}$, Nadiya Dubrovina ${ }^{4 *}$, Russell Gerrard ${ }^{5}$, Peter Labas $^{1}$, Olexander Gurov ${ }^{6}$, Olena Kozyreva ${ }^{7}$, Dmytro Hladkykh ${ }^{6}$, Yuliia Tkachenko ${ }^{6}$, Denis Zamiatin ${ }^{3}$ and Viktorija Borodina ${ }^{7}$

${ }^{1}$ Comenius University, Medical Faculty, Bratislava, Slovakia

${ }^{2}$ GI «V.T. Zaycev Kharkiv Research Institute of General and Emergency Surgery» of NAMS of Ukraine, Ukraine

${ }^{3}$ Kharkiv National Medical University, Ukraine

${ }^{4}$ University of Economics in Bratislava, Slovakia

${ }^{5}$ Cass Business School, City, University of London, UK

${ }^{6}$ Kharkiv Medical Academy of Post Diploma Education, Ukraine

${ }^{7}$ National University of Pharmacy, Ukraine

\section{Abstract}

Background: There are different approaches to the assessment of the severity of trauma in a victim and to the provision of specialized health care. Some of them are based on the development of scales and logistic models, using expert systems or statistical methods, to assess the severity of injury and the probability of a particular outcome. This article presents the results of a study on the feasibility of developing and applying various statistical models in order to predict the outcome in the case of different types of trauma, based on data on the status of victims with severe trauma.

Patients and methods: We present selected information about 373 victims, admitted and treated at the Department of Traumatic Shock of the GI «V.T. Zaycev Kharkiv Research Institute of General and Emergency Surgery» of NAMS of Ukraine; the records, which relate to patients with severe and combined trauma, were made between 1985 and 2015. The initial database contained 263 victims who had positive outcomes (survived), while 110 had fatal outcomes. Most of the patients presented with an open trauma ( 285 cases), then there were 80 cases with a closed injury and only 8 cases with a combined injury.

Results: To estimate the probability of the outcome for various types of trauma we have developed a predictive model, based on a logistic relationship. Categorical variables, indicating the presence or absence of various types of trauma, were used in the model. Information about the eventual outcome for a given victim with the indicated type of trauma was used as the dependent variable. The logit model which we obtained has a high predictive accuracy in predicting positive outcomes. Thus, based on the a posteriori analysis, $92 \%$ of cases in which victims survived were correctly recognized by the model. In view of the fact that abdominal trauma is the commonest of all trauma mechanisms, we constructed a predictive model to estimate the probability of various outcomes in the case of abdominal trauma or injury to certain organs of the abdominal cavity.

Linear discriminant functions were developed by us and used for the classification of possible outcomes depending on the condition of the victim and the resuscitation measures carried out. The model presented has a high predictive accuracy: on the basis of a posteriori analysis using data of discriminant functions, correct conclusions were drawn in $90 \%$ of cases when there was a positive outcome, and in $75 \%$ of cases when the outcome was fatal.

Conclusion: We conclude that it is reasonable to use the statistical model developed, along with other qualitative and quantitative methods of prognostic determination of outcomes for victims with severe injuries. As different models have different predictive accuracy and require the provision of different information, it is necessary to use a sufficiently large number of techniques to derive accurate predictions and to choose the right tactics for diagnosis and treatment.

Keywords: Injury; Prediction; Statistical models; Victims; Severe trauma; Trauma score

\section{Introduction}

In today's world the high level of injuries caused by anthropogenic risks, traffic accidents, natural disasters, terrorism and other factors, is one of the urgent problems for society and for the health system. There are different approaches for the timely assessment of the severity of a victim's trauma and for the provision of specialized medical care [15]. Some of them are based on the development of scales and logistic models, by using expert or statistical methods, to assess the severity of injury and the probabilities of the possible outcomes.

The best-known approaches are: AIS-90 (Abbreviated Injury Scale), ISS (Injury Severity Score), RTS (Revised Trauma Score), APACHE II (Acute Physiology and Chronic Health Evaluation), SAPS II (Simplified Acute Physiology Score), TRISS (Trauma and Injury Severity Score), ASCOT (A Severity Characterization of Trauma),
LODS (Logistic Organ Dysfunction Score), 24-hour ICU Trauma Score, TRIOS 4 (Three days Recalibrated ICU Outcomes Score), the Mortality Probability Model etc. [6-10].

As seen from the sources above, most of the predictive models which have been mentioned were developed by Western scholars; in some instances in the 70 s and 80 s. It should be noted that the

*Corresponding author: Dubrovina N, University of Economics, Bratislava Slovakia, Tel: +421 2/672 911 11; E-mail: nadija@mail.ru

Received October 03, 2016; Accepted May 27, 2017; Published August 28, 2017

Citation: Šteňo J, Boyko V, Zamiatin P, Dubrovina N, Gerrard R, et al. (2017) Prediction of Outcomes in Victims with Severe Trauma by Statistical Models. Biom Biostat 8: 366. doi: 10.4172/2155-6180.1000366

Copyright: ( 2017 Šteňo J, et al. This is an open-access article distributed under the terms of the Creative Commons Attribution License, which permits unrestricted use, distribution, and reproduction in any medium, provided the original author and source are credited. 
predictive models developed by Western scholars are not completely universal for the following reasons: the estimation, based on statistical methods, of the parameters and the characteristics of the models essentially depends on the model specification, features of the sample data, the characterization of the condition of the victims, the level of development of the national health system and emergency medical care.

Considering these factors, it is also reasonable to develop such models on the basis of contemporary national databases, which allow us to take into account the specifics of the level of development of the national health care and emergency medical services, characteristics of the condition of the victims, the most common trauma, complications, comorbidities, etc. Examples of such developments are the classification of the severity of traumatic shock proposed by Eryuhin and Shlyapnikov [11] and the logistic models obtained by Eid et al. for predicting the level of mortality of victims of traffic accidents, based on data from the Al Ain hospital in the United Arab Emirates. The current level of development of software packages of statistical programs and of expert systems permits the relatively rapid development of predictive models by any major hospital or specialized centre in Ukraine. At the same time, the full potential of modern statistical methods in medical and clinical research is not widely used in Ukraine, in contrast to the practice of leading Western centres, which have established analytical groups, professionally engaged in the collection and processing of data, and in the construction of predictive models and expert systems [12-16].

According to this, the task of developing native predictive models for the assessment of the severity of trauma, the probability of various outcomes and the indicators of the condition of the victims of different anthropogenic accidents, traffic accidents and other factors, is of current relevance in Ukraine $[17,18]$.

\section{Aim and Methods}

The aim of this study was the investigation of the possibility of developing and applying statistical models for the prediction of outcomes in the case of a number of types of trauma, based on data of the condition of victims admitted with severe combined trauma to the Traumatic Shock Department of the GI «V.T. Zaycev Kharkiv Research Institute of General and Emergency Surgery» of NAMS of Ukraine from 1985 to 2015.

\section{Patients}

Selective information about 373 victims was used as the initial data. $263(70.51 \%)$ of the victims had a positive outcome, while $110(29.49 \%)$ had a fatal outcome. The existing database contains information about victims with the following types of injury: open trauma: 285 cases (76.41\%); closed injury: 80 cases $(21.45 \%)$, combined injury: 8 cases (2.14\%). The age of the victims ranged from 7 years to 84 years; the distribution of ages was close to normal, and the median age was $34 \pm$ 1,17 years.

The causes of the injuries were as follows: S-i (stab-incised trauma): 261 cases (69.97\%); Gun (gunshot trauma): 27 cases (7.24\%), TA (d) (traffic accident - driver: 13 cases (3.49\%); TA (p) (traffic accident pedestrians): 18 cases (4.83\%); RW (railway trauma): 8 cases $(2.14 \%)$; Kat (katatrauma): 15 cases $(4.02 \%) ; B$ (beatings, bruises): 11 cases (2.95\%); SBM (struck by mechanisms): 11 cases (2.95\%), An (wounds caused by the bite of an animal): 3 cases $(0.8 \%)$ and Unkn (unknown cause of injury): 3 cases ( $0.8 \%)$.

In the research we used statistical methods for processing the clinical observation data and data on the results of operations and resuscitation measures, and also methods of statistical modelling (discriminant analysis, logistic (logit) modelling) for prediction of the outcomes in cases of severe polytrauma $(2,7,8,10)$.

The statistical data processing and the statistical model construction were conducted with the Statistica package and EViews.

\section{Results and Discussion}

According to the results of the available sample, the features of the distribution and the mode of received injuries were studied extensively. Thus, there were 154 cases of polytrauma $(41.29 \%) ; 243$ cases of abdominal trauma (65.15\%); 254 cases of chest trauma (68.1\%); 28 cases of craniocerebral trauma $(7.51 \%) ; 20$ cases of pelvic trauma (6.17\%); 23 cases of orthopedic trauma $(6.17 \%)$ and 6 cases of spinal trauma (1.61\%). Table 1 shows the distribution of types of trauma depending on the mechanism of trauma [19].

Sampling the data of 373 victims, used in our study, the following distribution of trauma of internal organs was observed: trauma of the lungs (TrL): 94 cases (25.2\%); trauma of the heart (TrH): 61 cases (16.35\%); trauma of the parenchymatous organs (TrParenh): 138 cases (37\%); trauma of the liver (TrLiv): 86 cases (23.06\%); trauma of the pancreas (TrPan): 31 cases (8.31\%); trauma of the hollow organs ( $\mathrm{TrHol}): 98$ cases (26.27\%) and trauma of the bowel (TrBow): 28 cases (7.51\%). Table 2 shows the distribution of outcomes depending on the type of trauma.

The status of the victim and the amount of medical care required affect the outcome. The ISS scale (Injury Severity Score) is often used to assess the severity of the trauma. Figure 1 shows the distribution of

\begin{tabular}{|c|c|c|c|c|c|c|}
\hline & \multicolumn{4}{|c|}{ Types of trauma } \\
\hline Trauma mechanisms & Polytrauma & Abdominal & Chest & Cranio-cervical & Pelvic & Orthopedic \\
\hline S-i & $79(30.27 \%)$ & $172(65.9 \%)$ & $171(65.52 \%)$ & $3(1.15 \%)$ & - \\
\hline Gun & $16(59.26 \%)$ & $18(66.67 \%)$ & $21(77.78 \%)$ & $2(7.41 \%)$ & $1(3.7 \%)$ & $1(3.7 \%)$ \\
\hline TA (d) & $11(84.62 \%)$ & $8(61.54 \%)$ & $12(92.31 \%)$ & $5(38.46 \%)$ & $2(15.38 \%)$ & $4(30.77 \%)$ \\
\hline TA (p) & $18(100 \%)$ & $10(55.56 \%)$ & $16(88.89 \%)$ & $9(50 \%)$ & $6(33.33 \%)$ & $8(44.44 \%)$ \\
\hline RW & $7(87.5 \%)$ & $5(62.5 \%)$ & $4(50 \%)$ & $1(12.5 \%)$ & $4(50 \%)$ & $3(37.5 \%)$ \\
\hline Kat & $7(46.67 \%)$ & $7(46.67 \%)$ & $11(73.33 \%)$ & $3(20 \%)$ & $4(26.67 \%)$ & $2(13.33 \%)$ \\
\hline B & $2(18.18 \%)$ & $9(81.82 \%)$ & $4(36.36 \%)$ & $1(9.09 \%)$ & $1(9.09 \%)$ & $1(9.09 \%)$ \\
\hline SBM & $6(54.55 \%)$ & $7(63.64 \%)$ & $8(72.73 \%)$ & $1(9.09 \%)$ & $1(9.09 \%)$ \\
\hline An & $3(100 \%)$ & $2(66.67 \%)$ & $3(100 \%)$ & $1(33.33 \%)$ & - \\
\hline Unkn & $2(66.67 \%)$ & $3(100 \%)$ & $1(33.33 \%)$ & - & - \\
\hline
\end{tabular}

Abbreviations: S-i: Stab-Incised Trauma, Gun: Gunshot Trauma, TA (d): Traffic Accident (driver), TA (p): Traffic Accident (pedestrians), RW: Railway Trauma, Kat: Katatrauma or Fall from Height, B: Beatings or Bruises, SBM: Stroke by Mechanisms, An: Wounds Caused by the Bite of an Animal, Unkn: Unknown Cause of Injury.

Table 1: Distribution of types of trauma depending on the mechanism of trauma 
Citation: Šteňo J, Boyko V, Zamiatin P, Dubrovina N, Gerrard R, et al. (2017) Prediction of Outcomes in Victims with Severe Trauma by Statistical Models. J Biom Biostat 8: 366. doi: 10.4172/2155-6180.1000366

Page 3 of 5

\begin{tabular}{|c|c|c|c|c|c|c|c|}
\hline \multirow{2}{*}{ Outcome } & \multicolumn{7}{|c|}{ Type of trauma } \\
\hline & Polytrauma & Abdominal & Chest & Cranio-cervical & Pelvic & Orthopedic & Spine \\
\hline $\mathrm{F}$ & $103(66.88 \%)$ & $168(69.14 \%)$ & 177 (69.69\%) & $19(67.86 \%)$ & $14(70.00 \%)$ & $15(65.22 \%)$ & $3(50 \%)$ \\
\hline A & $51(33.12 \%)$ & 75 (30.86\%) & $77(30.31 \%)$ & $9(32.14 \%)$ & $6(30.00 \%)$ & $8(34.78 \%)$ & $3(50 \%)$ \\
\hline All & $154(100 \%)$ & $243(100 \%)$ & $254(100 \%)$ & $28(100 \%)$ & $20(100 \%)$ & $23(100 \%)$ & $6(100 \%)$ \\
\hline
\end{tabular}

Abbreviations: F: Fatal Outcome, A: Positive Outcome.

Table 2: Distribution of outcomes depending on the type of trauma.

ISS

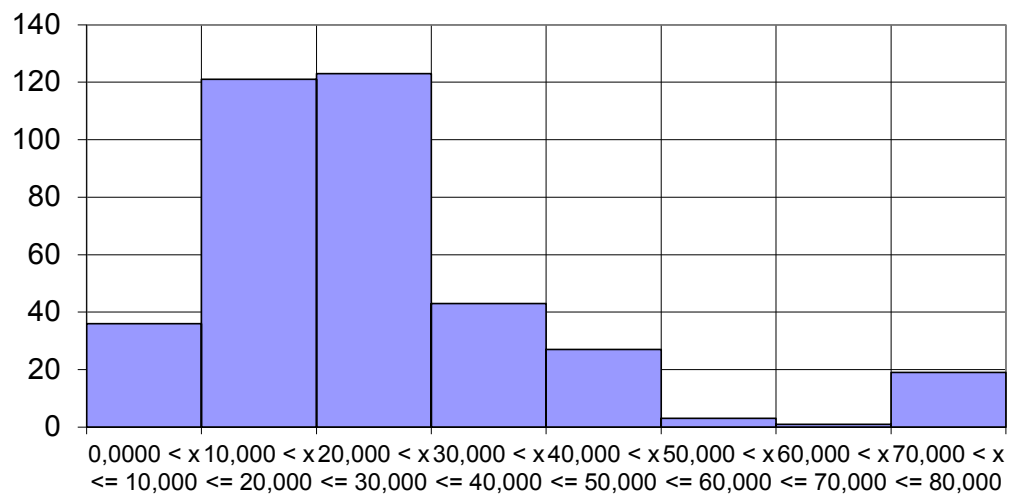

Figure 1: Distribution of victims by the level of severity of trauma (ISS scale)

victims in the original database by severity of trauma (on the ISS scale).

According to the distribution shown in Figure 1, 36 cases $(9.65 \%)$ fell into the interval where the values of the ISS were less than $10 ; 121$ $(32.44 \%)$ and $123(32.98 \%)$ cases fell in the intervals $10<I S S \leq 20$ and $30<$ ISS $\leq 40$ respectively; 43 cases $(11.53 \%)$ fell into the interval $30<$ ISS $\leq 40 ; 27$ cases $(7.24 \%)$ into the interval $40<I S S \leq 50 ; 3$ cases $(0.8 \%)$ into the interval $50<I S S \leq 60$, and the number of cases where the ISS value exceeded 60 was 20 (5.26\%). The average value of the ISS index in the sample for 373 victims was $25.99 \pm 1,53$. In the group of victims with a positive outcome the average value of ISS was $21.29 \pm 1.15$, and in the group of victims with a fatal outcome the average was $37.26 \pm 3.68$.

Application of Student's and Fisher's criteria to determine the statistical significance of the difference between the average ISS index for victims with positive and fatal outcomes revealed that there are significant differences of ISS between these groups (the value of Student's $t=-10.65$ with $p<0.01$, and the Fisher statistic $F=4.23$ with $p<0.01)$. The indicators of the degree of shock in the groups of victims were distributed as follows (Table 3 ).

As seen from the results shown in Table 3, in the case of a positive outcome $57.41 \%$ of the victims were characterized by a degree of shock from 0 to 2 , and in the cases with a fatal outcome more than half of victims (51.82\%) had the fourth degree of shock. At the same time, in the group of victims with a positive outcome $36.12 \%$ had the third degree of shock, while in the group with fatal outcome this figure was $34.55 \%$, i.e. there is similar incidence in these two groups. Nonparametric criteria (the sign criterion and the Wilcoxon criterion) revealed a statistically significant difference (with $p<0.01$ ) between the empirical distribution of the degree of shock in patients with a positive outcome and those with a fatal outcome.

To estimate the probability of the outcome for various trauma types we have developed a predictive model based on the logistic relationship, represented by the following expression:

\begin{tabular}{|c|c|c|c|c|}
\hline Outcome & \multicolumn{2}{|c|}{ Positive } & \multicolumn{2}{c|}{ Fatal } \\
\hline Degree of shock & Frequency & $\%$ & Frequency & $\%$ \\
\hline 0 & 20 & 7.6 & 1 & 0.91 \\
\hline 1 & 79 & 30.04 & 6 & 5.45 \\
\hline 2 & 52 & 19.77 & 8 & 7.27 \\
\hline 3 & 95 & 36.12 & 38 & 34.55 \\
\hline 4 & 17 & 6.46 & 57 & 51.82 \\
\hline
\end{tabular}

Table 3: Distribution of degree of shock in patients with different outcome.

$$
y=\frac{e^{c+c_{1} \cdot x_{1}+c_{2} \cdot x_{2}+\ldots+c_{n} \cdot x_{n}}}{1+e^{c+c_{1} \cdot x_{1}+c_{2} \cdot x_{2}+\ldots+c_{n} \cdot x_{n}}}
$$

Where $y$ is the estimate of the probability that the outcome will be positive, $c, c_{1}, c_{2}, \ldots, c_{n}$ are estimates of unknown model parameters calculated using the maximum likelihood method, and $x_{1}, x_{2}, \ldots, x_{n}$ represent a number of factors characterizing the condition of the victim, their personal history, etc. Factors may be quantitative or qualitative; in the latter case we make use of categorical variables, which take the value 1 if the sign (or symptom) is observed for the given victim and 0 otherwise. The factors used in the models should be independent or exhibit a low degree of correlation. In the case of strong correlation between factors, biased estimates of model parameters and incorrect signs might be obtained.

In this model, the value $y$ ranges from 0 to 1 ; the closer the calculated value is to 1 , the greater the probability that the victim will survive.

Table 4 presents estimates of the parameters of the logit model for prediction of the outcome for victims with various trauma types.

Categorical variables, indicating the presence or absence of various types of trauma, were used as factorial variables. The dependent variable was information about the outcome for a given victim with the indicated type of trauma, taking the value 1 in the case of a positive outcome and 0 in the case of a fatal outcome. As seen from the estimates, correct 
Citation: Šteňo J, Boyko V, Zamiatin P, Dubrovina N, Gerrard R, et al. (2017) Prediction of Outcomes in Victims with Severe Trauma by Statistical Models. J Biom Biostat 8: 366. doi: 10.4172/2155-6180.1000366

Page 4 of 5

\begin{tabular}{|c|c|c|c|c|c|}
\hline $\begin{array}{c}\text { Variable (reference } \\
\text { designation) }\end{array}$ & \multirow[t]{2}{*}{ Meaning of variable (factorial sign) } & $\begin{array}{l}\text { Estimate of } \\
\text { parameter }\end{array}$ & Standard deviation & \multirow[t]{2}{*}{ z-Statistics } & \multirow{2}{*}{$\begin{array}{c}\text { p-level } \\
\text { Prob. }\end{array}$} \\
\hline Variable & & Coefficient & Std. Error & & \\
\hline $\mathrm{C}$ & Constant & 1.524715 & 0.542393 & 2.811086 & 0.0049 \\
\hline D15 & Polytrauma & -0.340150 & 0.529008 & -0.642995 & 0.5202 \\
\hline D16 & Abdominal trauma (AbdomTr) & 0.194211 & 0.581121 & 0.334201 & 0.7382 \\
\hline D17 & Chest trauma (ChestTr) & 0.520494 & 0.559294 & 0.930627 & 0.3520 \\
\hline D18 & Craniocerebral trauma (Cr-Cer.Tr) & 0.710541 & 0.537810 & 1.321175 & 0.1864 \\
\hline D19 & Pelvic trauma (PelvTr) & -0.037213 & 0.622768 & -0.059754 & 0.9524 \\
\hline D20 & Orthopedic trauma (OrthopTr) & 0.057394 & 0.590155 & 0.097252 & 0.9225 \\
\hline D21 & Spinal trauma (SpinTr) & -0.841292 & 0.986316 & -0.852964 & 0.3937 \\
\hline D28 & trauma of lungs (TrL) & -1.168893 & 0.317405 & -3.682658 & 0.0002 \\
\hline D29 & trauma of heart $(\mathrm{TrH})$ & -1.471274 & 0.340561 & -4.320146 & 0.0000 \\
\hline D30 & Trauma of parenchymatous organs (TrParenh) & -0.031516 & 0.501797 & -0.062807 & 0.9499 \\
\hline D31 & Trauma of liver (TrLiv) & -0.571780 & 0.461612 & -1.238660 & 0.2155 \\
\hline D32 & Trauma of pancreas (TrPan) & -1.886609 & 0.514268 & -3.668535 & 0.0002 \\
\hline D33 & Trauma of hollow organs (TrHol) & 0.049987 & 0.378534 & 0.132054 & 0.8949 \\
\hline D34 & Trauma of bowel (TrBow) & -1.144548 & 0.529621 & -2.161072 & 0.0307 \\
\hline
\end{tabular}

Table 4: Estimates of parameters of logit model for prediction of the outcome for victims with various trauma types.

\begin{tabular}{|c|c|c|c|c|c|}
\hline $\begin{array}{l}\text { Variable (reference } \\
\text { designation) }\end{array}$ & \multirow[t]{2}{*}{ Meaning of variable (factorial sign) } & $\begin{array}{l}\text { Estimate of } \\
\text { parameter }\end{array}$ & Standard deviation & \multirow[t]{2}{*}{ z-Statistics } & \multirow{2}{*}{\begin{tabular}{|l} 
p-Level \\
Probability
\end{tabular}} \\
\hline Variable & & Coefficient & Std. error & & \\
\hline $\mathrm{C}$ & Constant & 7.536723 & 0.862621 & 8.737004 & 0.0000 \\
\hline AGE & Age & -0.057595 & 0.013014 & -4.425768 & 0.0000 \\
\hline D16 & Abdominal trauma (AbdomTr) & 0.476250 & 0.432612 & 1.100870 & 0.2710 \\
\hline D30 & Trauma of parenchymatous organs (TrParenh) & 0.216656 & 0.616793 & 0.351261 & 0.7254 \\
\hline D31 & Trauma of liver (TrLiv) & -0.203177 & 0.549646 & -0.369651 & 0.7116 \\
\hline D32 & Trauma of pancreas (TrPan) & -0.986243 & 0.570621 & -1.728369 & 0.0839 \\
\hline D34 & Trauma of bowel (TrBow) & -0.832464 & 0.570490 & -1.459208 & 0.1445 \\
\hline D37 & Peritonitis & -1.411723 & 0.553587 & -2.550135 & 0.0108 \\
\hline ISS & Injury Severity Score & -0.071683 & 0.015300 & -4.685142 & 0.0000 \\
\hline SHOCK_LEVEL & Degree of shock severity & -0.993547 & 0.173797 & -5.716700 & 0.0000 \\
\hline
\end{tabular}

Table 5: Estimates of logit model parameters predicting the outcome for victims with abdominal trauma.

signs were obtained for most factors, while estimates of the parameters are statistically significant at the $5 \%$ level for the factors D28 (trauma of the lung), D29 (trauma of the heart), D32 (trauma of the pancreas) and D34 (trauma of the bowel). In all of these cases the parameter estimates are negative, demonstrating that these factors have the effect of reducing the probability of the victim's survival.

The logit model obtained by us has a high predictive accuracy in predicting positive outcomes. Thus, based on the a posteriori analysis, $92 \%$ of cases in which victims survived were correctly recognized by the model. Since abdominal trauma is the commonest of all mechanisms of trauma, we constructed a predictive model to estimate the probability of various outcomes in instances of abdominal trauma and injury of certain organs of the abdominal cavity. The parameter estimates for this model are shown in Table 5.

As seen from the results, correct by sign and statistically significant estimates of parameters were obtained at the $5 \%$ level in most factorial signs. It is confirmed analytically that the chances of survival are significantly reduced in the presence of peritonitis, trauma of the pancreas and bowel, or a high degree of shock severity. Also, the probability of survival declines with increasing age and increasing value on the ISS scale.

The logit model which we have fitted has a high degree of accuracy in predicting positive outcomes. Thus, based on a posteriori analysis, more than $90 \%$ cases of abdominal trauma, where victims survived, were correctly recognized by the model. Linear discriminant models can be used for the classification of possible outcomes. Table 6 shows the results of the construction of linear discriminant functions for the classification of possible outcomes depending on the condition of the victim and the resuscitation measures attempted.

In the case of a positive outcome the discriminant function looks as follows:

$D(A)=-109.606+0.7794 . Z 1-0.4886 . Z 2-3.8099 . Z 3+0.0117$. $Z 4+0.0091 . Z 5$

$+0.9783 . Z 6+0.9082 . Z 7+0.6834 . Z 8-0.1984 . Z 9+0.9641 . Z 10-0.2622 . Z 11$

In the case of a fatal outcome the discriminant function looks as follows:

$D(F)=-129.253+1,5358 . Z 1-0.8649 . Z 2-4.1362 . Z 3+0.0031$. $Z 4+0.0186 . Z 5$

\section{$+1.3046 . Z 6+1.2365 . Z 7+0.8506 . Z 8-0.3803 . Z 9+1.1198 . Z 10-0.3428 . Z 11$}

The most probable outcome is determined by evaluating both discriminant functions and choosing whichever is largest. The discriminant model we have obtained is statistically robust, as evidenced by the value of Fischer's F-statistic $(F(11,19)=5.3764$, giving $\mathrm{p}<0.0007$ ) and the acceptable value of Wilks's lambda (equal to 0.243 ). The model presented has a high predictive accuracy: on the basis of a posteriori analysis based on our discriminant functions, we obtain 
Citation: Šteňo J, Boyko V, Zamiatin P, Dubrovina N, Gerrard R, et al. (2017) Prediction of Outcomes in Victims with Severe Trauma by Statistical Models. J Biom Biostat 8: 366. doi: 10.4172/2155-6180.1000366

Page 5 of 5

\begin{tabular}{|c|c|c|c|}
\hline \multirow{3}{*}{$\begin{array}{l}\text { Variable (reference } \\
\text { designation) }\end{array}$} & \multirow{3}{*}{ Meaning of variable } & \multicolumn{2}{|c|}{ Outcome } \\
\hline & & A & $\mathbf{F}$ \\
\hline & & $p=0.83871$ & $p=0.16129$ \\
\hline $\mathrm{Z1}$ & DUR APV- Duration of artificial pulmonary ventilation (APV) & 0.77943 & 1.53581 \\
\hline $\mathrm{Z2}$ & BP END OP - Blood Pressure at the end of operation & -0.48866 & -0.86490 \\
\hline Z3 & T BEFORE HOSP - Time before hospitalization & -3.80990 & -4.13625 \\
\hline Z4 & VOL OF HEM - Volume of hemorrhage & 0.01175 & 0.00315 \\
\hline $\mathrm{Z} 5$ & VOL OF REINF - Volume of reinfusion & 0.00909 & 0.01860 \\
\hline Z6 & SP OF I/V INF Speed of i/v infusion during the operation & 0.97838 & 1.30466 \\
\hline $\mathrm{Z7}$ & BP BEFORE OP - BP before operation & 0.90825 & 1.23652 \\
\hline Z8 & MAX BP DUR OP - Maximal BP during operation & 0.68347 & 0.85067 \\
\hline Z9 & MIN BP DUR OP - Minimal BP during operation & -0.19844 & -0.38035 \\
\hline Z10 & AD AT ARRIV - BP at the arrival & 0.96413 & 1.11981 \\
\hline Z11 & T BEFORE RES - Time before the beginning of resuscitation measures & -0.26222 & -0.34280 \\
\hline Constant & Constant & -109.606 & -129.253 \\
\hline
\end{tabular}

Table 6: Estimates of model parameters of discriminant functions for prediction of outcome based on a number of indicators characterizing the condition of the victim and the resuscitation measures attempted.

correct conclusions in $90 \%$ of cases when there was a positive outcome, and in $75 \%$ of cases, when the outcome was fatal.

\section{Conclusions}

It is reasonable to use the predictive models described in this study alongside other qualitative and quantitative methods to predict the outcome for patients with severe trauma. As different models have different predictive accuracy and require different information provision, it is necessary to use a sufficiently large number of techniques to obtain accurate predictions and to choose the right methods for diagnosis and treatment. Considering the complexity of computational procedures for the use of certain techniques or scales, Ukraine needs to develop and implement automated expert systems that can process large amounts of information about each victim, monitor the outcome of the treatment and assess its effectiveness.

\section{Acknowledgments}

This paper is the result of the research project "Crisis Management in Organizational Measures, Technical and Staff Health Care Capacities on Natural and Technical Disasters in SR, PL and UA" co-financed by International Visegrad Fund.

\section{References}

1. Barbiera F, Nicastro N, Finazzo M, Lo Casto A, Runza G, et al. (2003) The role of MRI in traumatic rupture of the diaphragm. Radiol Med Torino 3: 188-194.

2. Basoglu A, Akdag AO, Celik B, Demircan S (2004) Thoracic trauma: an analysis of 521 patients. Ulus Travma Derg 1: 42-46.

3. Bialik EI, Sokolov VA, Semenova MN, Yevdokimova NV (2003) Features of the treatment of open fractures of long bones in patients with polytrauma. Issue of trauma 3: 3-9.

4. EViews (2000) User's Guide. Quantitative Micro Software, LLC, New York, p: 691.Kudera JS, Aanning HL (2004) Damage control for blunt hepatic trauma: case presentation and historical review. J Med 57: 449-453.

5. Baker SP, Bergstresser PR, Jacobe HT (1974) The injury severity score: a method for describing patients with multiple injuries and evaluating emergency care. J Trauma 3: 187-196.

6. Borovikov VP (2001) Statistica: the art of data analysis on the computer. Publishing House "Piter", SPb, 2001, p: 656.

7. Hill IR (1987) The Air India jumbo jet disaster. Uses of forensic sciences. Edinburgh. Scottish Academic Press, pp: 120-145.

8. Simpson H (1997) Road Accidents Great Britain: The Casualty Report Department of the Environment, Transport and the Regions. National Hospital Study of Road Accidents, p: 76.

9. Eryukhin IA, Shlyapnikov SA (1997) Extreme body condition. Aesculapius, SPb
10. Boyko VV, Zamiatin PN, Yakovcov IZ (2011) Analysis of heavy mechanical damage in patients with traumatic illness. Experiental Clinical Medicine 53 143-146.

11. Borovikov VP, Borovikov IP (1997) Statistica-Statistical analysis and data processing on Windows. Information and Publishing House "Filin", Moscow.

12. Bull JP (1975) The injury severity score of road traffic casualties in relation to mortality, time of death, hospital, treatment and disability. Accident Analysis and Prevention 4: 249-255.

13. Kruglov VV, Borisov VV (2002) Artificial Neural Networks. Theory and practice. Hotline - Telecom, p: 382.

14. Lapach SN, Chubenko AV, Babich PN (2000) Statistical methods in biomedica research using Excel. MORION, Kiev, p: 320.

15. Eid HO, Yan HH, Du HH, Huang HR (2008) Factors affecting anatomical region of injury, severity, and mortality for road trauma in a high-income developing country: Lessons for prevention. Injury 2: 22-34.

16. Forsythe RM, Harbrecht BG, Peitzman AB (2006) Blunt splenic trauma. Scand J Surgery 95: 146-151.

17. Abakumov MM, Lebedev NV, Malyarchuk VI (2005) Abdominal injuries in associated trauma. Medicine, Moscow.

18. Dubrov AM, Mkhitaryan VS,Troshin LI (1998) Multivariate statistical methods. Finance and Statistics. 